\title{
SECÇÃo ÓtIMA
}

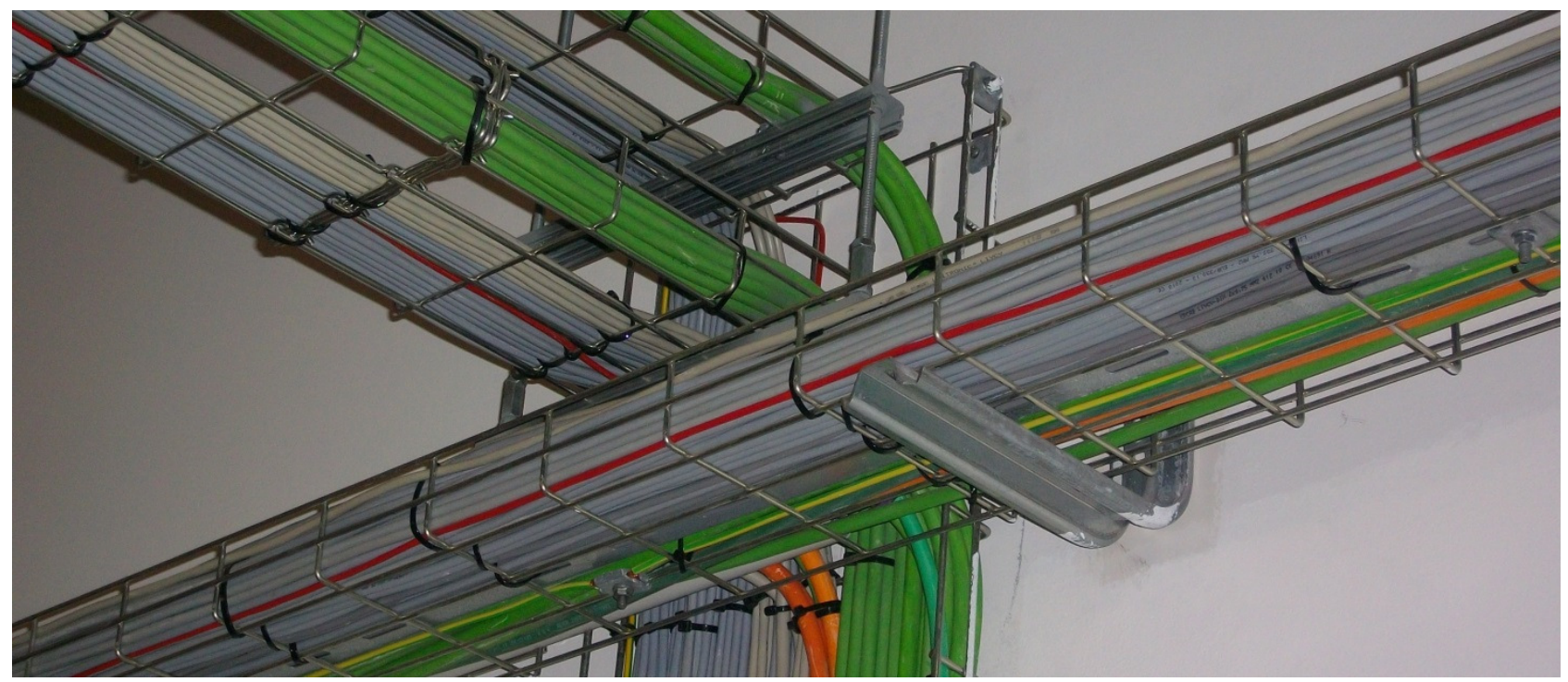

\section{Introdução}

Nem sempre a secção definida ou tabelada como "mínima" para uma determinada corrente de serviço é a secção ótima para executar um circuito. Esta secção dependerá do valor da carga e da quantidade de tempo a que está sujeita, podendo compensar economicamente executar o circuito com uma secção superior, obtendo-se o retorno do investimento com a redução das perdas por efeito de Joule.

\section{Secção ótima de um circuito monofásico}

Ponderar se compensa executar um circuito com uma secção superior à estipulada ou à mínima tabelada, passa por relacionar o investimento acrescido numa secção superior com o eventual ganho em eficiência que se alcançará. Para tal, ter-se-á que contar com o custo dos condutores e sobretudo estimar a eficiência do circuito a alimentar considerando as duas secções em ponderação. Esta relação de custo com eficiência irá permitir calcular o retorno do investimento em número de anos, ou seja, o tempo que levará a pagar o investimento acrescido realizado.
O retorno do investimento para um circuito monofásico, o chamado Payback, é dado pela expressão seguinte:

$$
\text { Payback }_{\text {anos }}=\frac{\text { Investimento adicional em condutores }}{\text { Poupança adicional em Perdas }}
$$

Em que:

- O "Investimento adicional em condutores" representa o encargo acrescido para se executar o circuito com uma secção superior;

- A "Poupança adicional em perdas" representa a poupança em perdas por efeito de Joule por ano, valorizadas ao preço do kWh, por se optar por condutores de secção superior, logo com menos perdas".

Assim, o Payback em anos poderá ser obtido da seguinte forma:

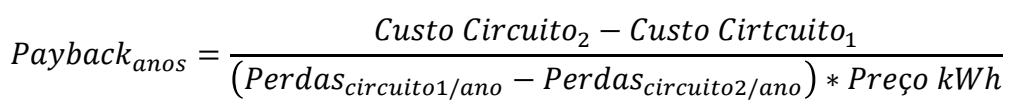

Considerando que as perdas por efeito de Joule são dadas pela expressão:

$$
P=R * I^{2} \text { sendo } R=\frac{\rho * L}{S}
$$


A expressão do Payback poderá ser obtida da seguinte forma:

Payback $_{\text {anos }}=\frac{\text { Custo Circuito }_{2}-\text { Custo Cirtcuito }_{1}}{2 * I^{2} * \rho * L *\left(\frac{1}{S_{1}}-\frac{1}{S_{2}}\right) * \frac{1}{1000} * h * 365 * \text { Preço } k W h_{h}}$
Para a corrente e comprimento em causa e de acordo com as tabelas da corrente máxima admissível dos condutores nos vários modos de instalação (RTIEBT), a secção de $2,5 \mathrm{~mm}^{2}$ será suficiente para alimentar uma carga de $2000 \mathrm{~W}$.

A questão é:

Será que compensará, economicamente, optar por um condutor de $4 \mathrm{~mm}^{2}$, ou apenas em algumas condições se torna vantajoso optar por esta secção?

Resistência do condutor $2,5 \mathrm{~mm}^{2} \Rightarrow R=\frac{\rho L}{S}=0,135 \Omega$

Resistência do condutor $4 \mathrm{~mm}^{2} \Rightarrow R=\frac{\rho L}{S}=0,084 \Omega$

As perdas por efeito de Joule instantâneas serão, por condutor:

Perdas $_{\text {Condutor } 1}=R_{C 1} * I^{2}=10,22 W$

Perdas $_{\text {Condutor } 2}=R_{C 2} * I^{2}=6,36 \mathrm{~W}$

Sendo o circuito monofásico, a corrente no condutor neutro é igual à corrente no condutor de fase, ou seja, as perdas por efeito de Joule são iguais em ambos os condutores, consequentemente o conjunto das perdas no circuito será o dobro das verificadas no condutor de fase:

$\operatorname{Perdas}_{C 1}=2 * R_{C 1} * I^{2}=20,44 W$

$\operatorname{Perdas}_{C 2}=2 * R_{C 2} * I^{2}=12,72 W$

A tabela 1 faz um resumo do anteriormente referido. que irá definir a corrente que percorrerá os condutores, estando diretamente relacionada com as perdas por efeito de Joule.

$$
I=\frac{P}{U}=\frac{2000}{230}=8,7 \mathrm{~A}
$$

Tabela 1 - Resumo das perdas nos condutores

\begin{tabular}{|c|c|c|c|}
\hline & $\begin{array}{l}\text { Resistência } \\
\text { do condutor }\end{array}$ & $\begin{array}{l}\text { Perdas no } \\
\text { condutor }\end{array}$ & $\begin{array}{c}\text { Perdas no } \\
\text { circuito }\end{array}$ \\
\hline $\begin{array}{c}\text { Circuito } 1 \\
\text { Condutor } 2,5 \mathrm{~mm}^{2}\end{array}$ & $0,135 \Omega$ & $10,22 \mathrm{~W}$ & $20,44 \mathrm{~W}$ \\
\hline $\begin{array}{c}\text { Circuito } 2 \\
\text { Condutor } 4 \mathrm{~mm}^{2}\end{array}$ & $0,084 \Omega$ & $6,36 \mathrm{~W}$ & $12,72 \mathrm{~W}$ \\
\hline
\end{tabular}


Por cada período de 1 hora de utilização do circuito, as perdas por efeito de Joule serão:

$\operatorname{Perdas}_{C 1}=2 * R_{C 1} * I^{2}=20,44 W h$

$\operatorname{Perdas}_{C 2}=2 * R_{C 2} * I^{2}=12,72 W h$

Se se considerar uma utilização de uma hora diária, durante um ano (365 horas) as perdas acumuladas serão respetivamente de:

$\operatorname{Perdas}_{C 1}=20,44 W \mathrm{Wh} * 365$ dias $=7,77 \mathrm{kWh}$

$\operatorname{Perdas}_{C 2}=12,72 \mathrm{Wh} * 365$ dias $=4,64 \mathrm{kWh}$
Supondo que a utilização é intensiva, por exemplo, num comércio ou numa indústria em que a utilização é muito superior podendo atingir 8 horas por dia em carga, as perdas acumuladas anualmente serão nesta situação:

$$
\begin{aligned}
& \operatorname{Perdas}_{C 1}=20,44 \mathrm{Wh} * 365 \text { dias } * 8 \text { horas }=62,16 \mathrm{kWh} \\
& \operatorname{Perdas}_{C 2}=12,72 \mathrm{Wh} * 365 \text { dias } * 8 \text { horas }=37,12 \mathrm{kWh}
\end{aligned}
$$

A tabela 2 faz um resumo do anteriormente referido.

Tabela 2 - Perdas nos condutores para as diversas situações de utilização dos circuitos

\begin{tabular}{|c|c|c|c|c|}
\hline & 1 Hora & $\mathbf{8}$ Horas & 1 Hora por dia por ano & 8 Horas por dia por ano \\
\hline Perdas C1 & $20,44 \mathrm{Wh}$ & $163,52 \mathrm{Wh}$ & $7,77 \mathrm{kWh}$ & $62,16 \mathrm{kWh}$ \\
\hline Perdas C2 & $12,72 \mathrm{Wh}$ & $101,76 \mathrm{Wh}$ & $4,64 \mathrm{kWh}$ & $37,12 \mathrm{kWh}$ \\
\hline
\end{tabular}

Considerando o preço por kWh da tarifa regulada em 2013 de $0,14 € / k W h$ (sem IVA) o custo em perdas é, para as várias situações, o indicado na tabela 3:

Tabela 3 - Custos das perdas nos condutores para as diversas situações de utilização dos circuitos

\begin{tabular}{|c|c|c|c|c|} 
& $\begin{array}{c}\text { 1 Hora por } \\
\text { dia por ano }\end{array}$ & $\begin{array}{c}\mathbf{8} \text { Horas por dia } \\
\text { por ano }\end{array}$ & $\begin{array}{c}\text { 1 Hora por dia durante } 10 \\
\text { anos }\end{array}$ & $\begin{array}{c}\mathbf{8} \text { Horas por dia durante } 10 \\
\text { anos }\end{array}$ \\
\hline Perdas C1 & $1,04 €$ & $8,35 €$ & $10,43 €$ & $83,46 €$ \\
\hline Perdas C2 & $0,62 €$ & $5,22 €$ & $4,35 €$ & $52,16 €$ \\
\hline
\end{tabular}

Então, do ponto de vista económico, em que situações compensará executar o circuito com condutores de $2,5 \mathrm{~mm}^{2}$ ou de $4 \mathrm{~mm}{ }^{2}$ de secção?

Considerando um custo médio dos condutores (sem IVA), conforme indicado na tabela 4:

Tabela 4 - Custo médio dos condutores (sem IVA)

\begin{tabular}{|c|c|c|c|}
\hline & $\begin{array}{c}1 \text { metro de } \\
\text { condutor }\end{array}$ & $\begin{array}{c}15 \text { metros de } \\
\text { condutor }\end{array}$ & $\begin{array}{c}15 \text { metros } \\
3 \text { condutores }\end{array}$ \\
\hline Condutor $2,5 \mathrm{~mm}^{2}$ & $0,36 €$ & $5,4 €$ & $16,2 €$ \\
\hline Condutor $4 \mathrm{~mm}^{2}$ & $0,56 €$ & $8,4 €$ & $25,2 €$ \\
\hline
\end{tabular}

O "custo dos condutores" deverá ser o custo para o cliente final, pois é este que terá de compensar o investimento adicional com a poupança nas perdas por efeito de Joule. 
Sendo o cálculo do Payback dado pela expressão:

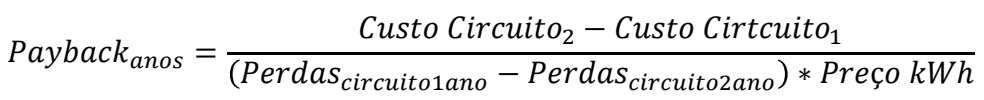

Nota: Duas das variáveis dependem de "custos", o Custo do Circuito e o Custo do kWh, se ambas forem variando anualmente com base na inflação, não terá impacto no Payback do investimento.
Aplicado ao exemplo em análise, executar o circuito com condutores de $2,5 \mathrm{~mm}^{2}$ terá um custo inicial de 16,2€ e executar o circuito com condutores de $4 \mathrm{~mm}^{2}$ terá um custo de $25,2 €$.

Payback $_{1 \text { dia }}=\frac{\text { Investimento adicional em condutores }}{\text { Poupança adicional em Perdas }}=\frac{25,2-16,2}{1,04-0,62}=21,43$ Anos

Payback $_{8 h \text { dia }}=\frac{\text { Investimento adicional em condutores }}{\text { Poupança adicional em Perdas }}=\frac{25,2-16,2}{8,35-5,22}=2,88$ Anos
No entanto, se se verificar o que tem acontecido nos últimos anos, ou seja, o preço da energia tem tido uma subida superior à inflação, significa que a energia vai ficando mais cara relativamente ao custo dos condutores, existindo assim uma grande probabilidade do Payback em anos vir a ser menor do que o inicialmente estimado.
Conclui-se assim que, se se considerar uma utilização diária de uma hora durante 365 dias, a secção ótima será a secção mínima tabelada $2,5 \mathrm{~mm}^{2}$; no entanto, se o circuito tiver uma utilização intensiva, tomando por exemplo as 8 horas por dia, a secção ótima é $4 \mathrm{~mm}^{2}$ e não a mínima regulamentar.

Payback em anos

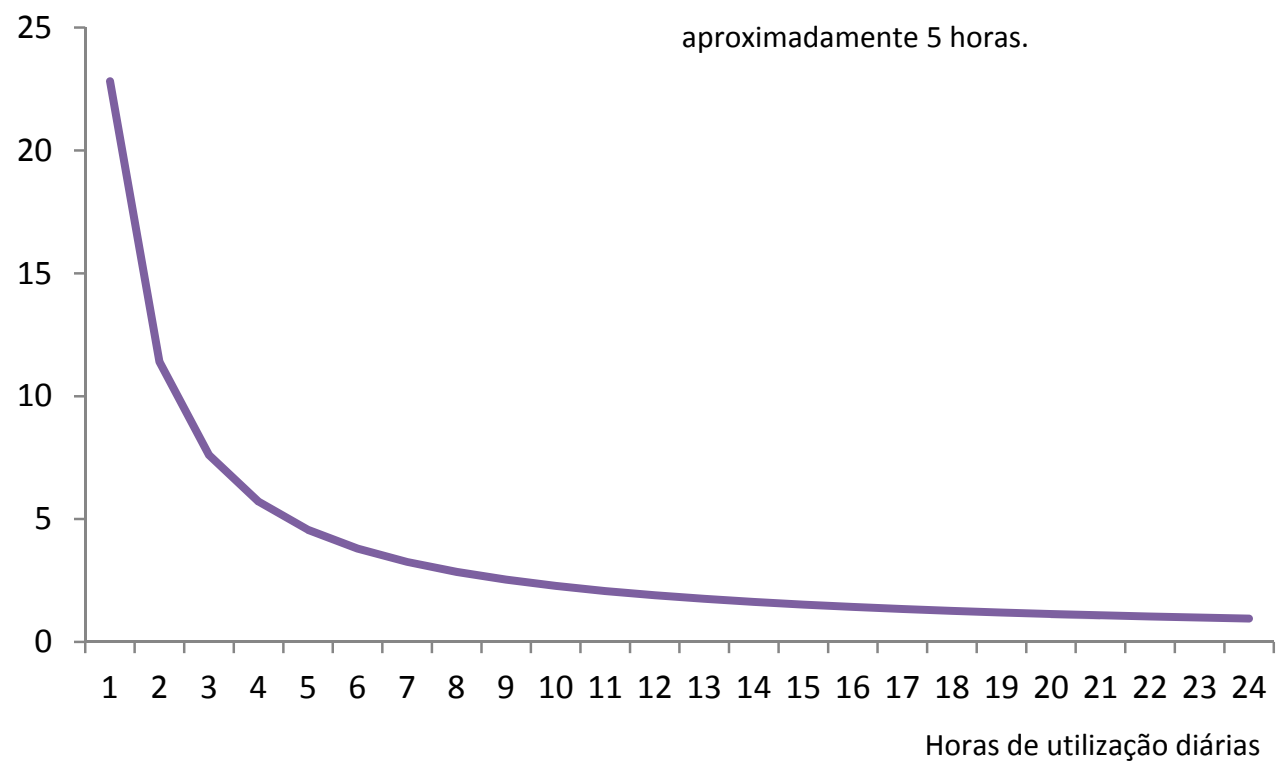

O gráfico 1 mostra o Payback do investimento em função da utilização diária.

Analisando o gráfico, considerando uma carga com uma potência de 2000W, se se pretender "oferecer" um Payback de 10 anos, seria necessária uma utilização de aproximadamente 2 horas e meia diárias. Já para um Payback de 5 anos, implicaria uma utilização diária de aproximadamente 5 horas.

Gráfico 1 - Payback do investimento em função da utilização diária 
Se se pretender "oferecer" um Payback em função das horas de utilização diárias necessárias e da potência do circuito, estas poderão

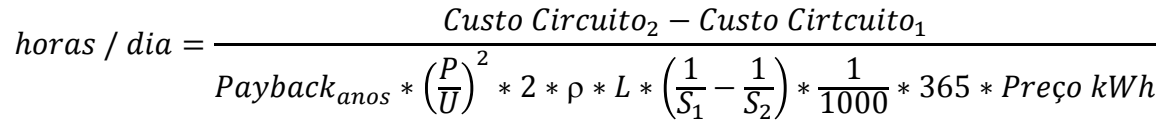
ser calculadas da seguinte forma:

Se o resultado da quantidade de horas de utilização diárias necessária for:

- Superior a 24 horas diárias, significa que será impossível alcançar o Payback desejado;

- Inferior a 24 horas diárias, mas superior à utilização expectável, o Payback desejado não será alcançado;

- Igual às horas de utilização expectáveis, o Payback desejado será alcançado no tempo desejado;

- Inferior a 24 horas diárias e inferior à utilização expectável, o Payback desejado será alcançado antes do tempo desejado.

A tabela 5 faz um resumo do anteriormente referido.
Relativamente à influência que as restantes variáveis têm sobre o Payback do investimento:

- Quanto mais baixo for o custo dos condutores, menor será a quantidades de horas de utilização diária necessária;

- Quanto maior for a Potência P do circuito, menos horas de utilização diária serão necessárias;

- Quanto maior for o comprimento L, maiores serão as perdas nos condutores, pelo que serão necessárias menos horas de utilização diária;

- Quanto maior for o preço do kWh, menos horas de utilização diária serão necessárias.

Tabela 5- Payback em função das horas de utilização

\begin{tabular}{c|c|c|c|c|c|} 
Horas de utilização $h$ & $h>24$ & $24>h>0$ e $h>$ expectável & $24>h>0$ e $h=$ expectável & $24>h>0$ e $h<$ expectável \\
\hline
\end{tabular}

\begin{tabular}{|l|l|l|l|l|}
\hline O Payback será & Impossível & Impossível & Alcançado
\end{tabular}

A título de exemplo, se se considerar uma utilização diária de 8 horas, o Payback em função da potência do circuito é o indicado no gráfico 2.

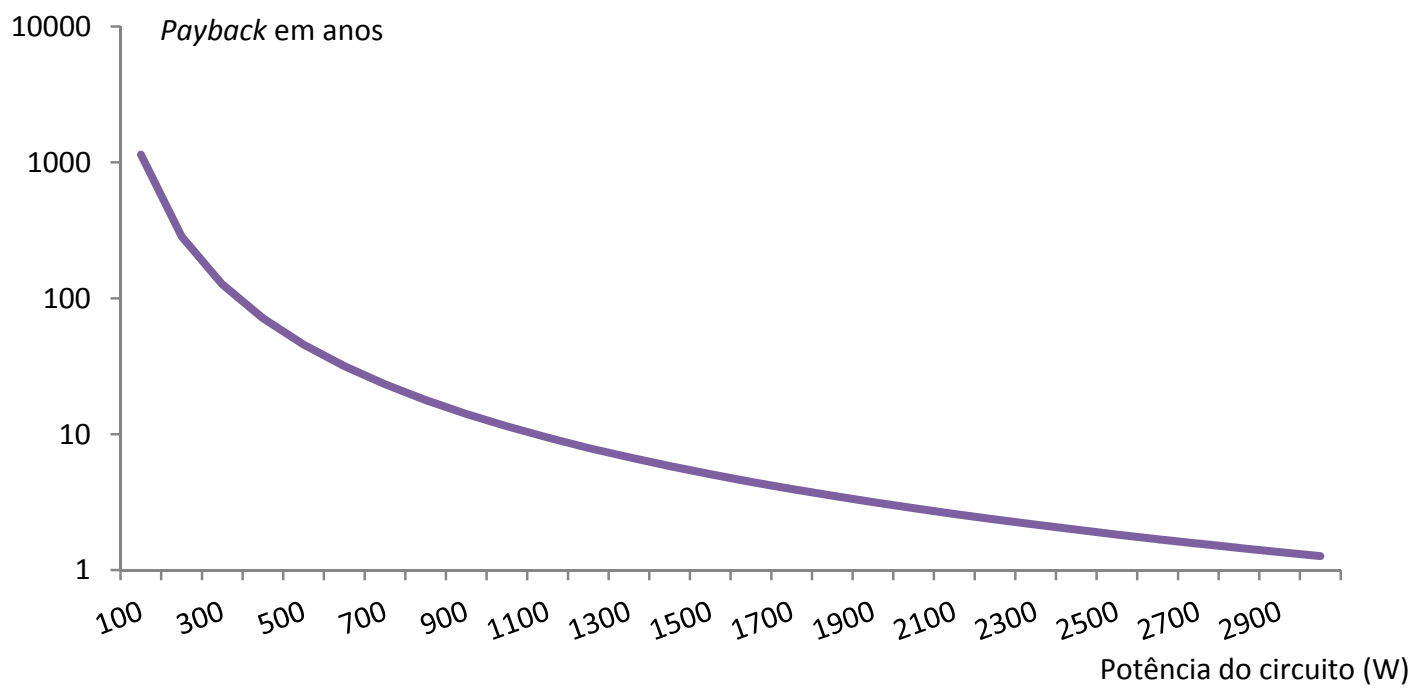

Gráfico 2 - Payback do investimento em função da potência do circuito 
Ou seja, se se considerar 10 anos como um Payback aceitável, só a partir de uma potência de $1200 \mathrm{~W}$ é que compensaria executar o circuito com uma secção superior. combinações "Horas de utilização Vs Potência do circuito" que justificariam o investimento e a área a vermelho, as combinações que não compensariam o investimento.

Por fim, se se considerar o Payback de 10 anos como "aceitável", a área a verde, da figura 1, representa as

Potência em W

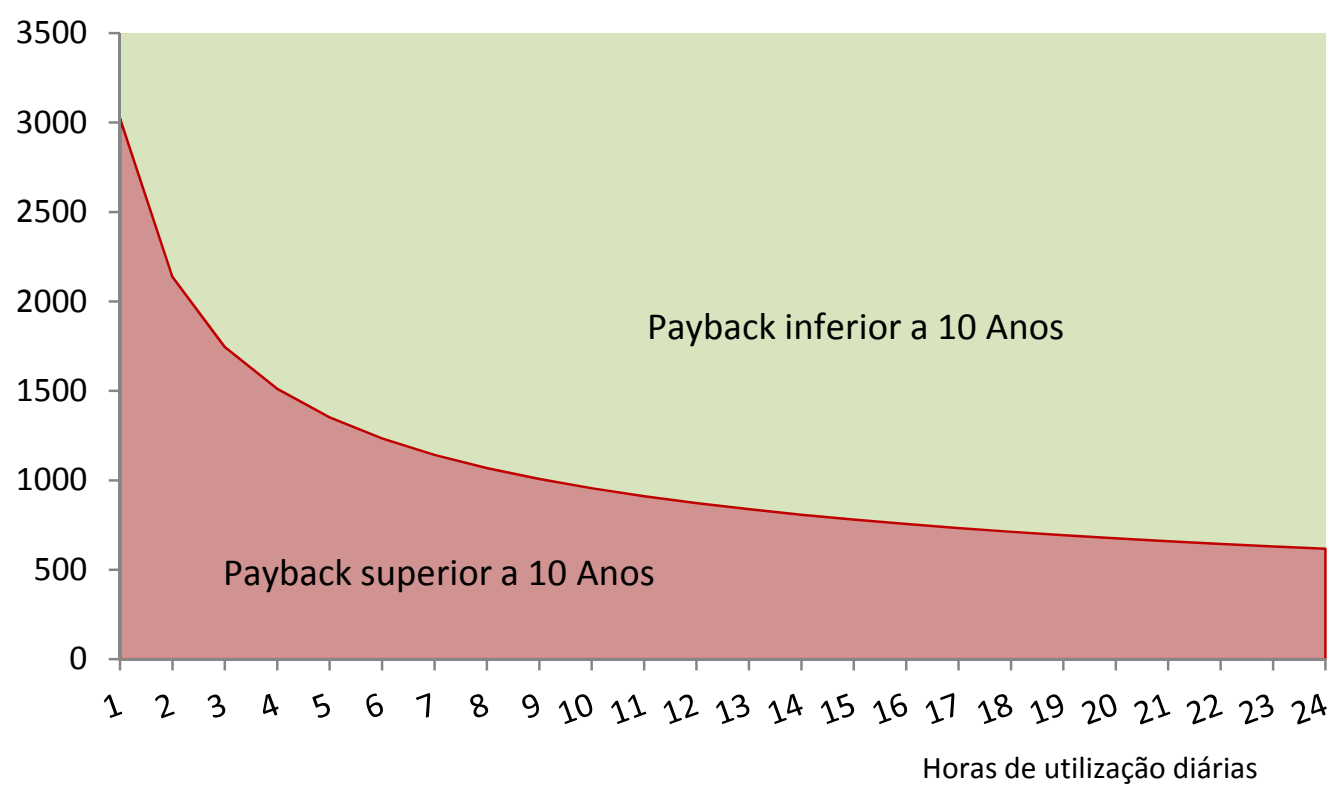

Figura 1 - Payback do investimento em função da potência e das horas diárias de utilização

Simplificação do cálculo:

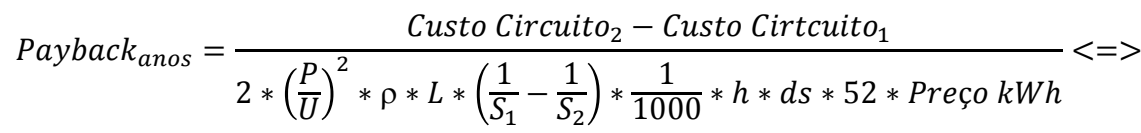

$$
\begin{aligned}
& \text { Payback }_{\text {anos }}=\frac{3 * L *\left(\text { Custo por metro }_{2}-\text { Custo por metro }_{1}\right)}{2 *(I)^{2} * L *\left(R_{1 / \text { metro }}-R_{2 / \text { metro }}\right) * \frac{52}{1000} * h * d s * \text { Preço } k W h}<=> \\
& \text { Payback }_{\text {anos }}=\frac{3 *\left({\text { Custo por } \text { metro }_{2}-\text { Custo por metro }}_{1}\right)}{2 *(I)^{2} *\left(R_{1 / \text { metro }}-R_{2 / \text { metro }}\right) * \frac{52}{1000} * h * d s * \text { Preço } k W h}<=>
\end{aligned}
$$

A fórmula simplificada para o cálculo do Payback em monofásico será então:

$$
\text { Payback }_{\text {anos }}=\frac{28,85 *\left(\text { Custo por } \text { metro }_{2}-\text { Custo por metro } \text { m }_{1}\right)}{(I)^{2} *\left(R_{1 / \text { metro }}-R_{2 / \text { metro }}\right) * h * d s * \text { Preço } k W h}
$$


Para se obter o Payback em anos, dever-se-á inserir o "Custo por metro" de cada um dos condutores (onde o índice 1 é a secção mínima e o índice 2 a secção a ponderar), a corrente "I" (em função da potência da carga a alimentar), as horas de utilização diárias previsíveis " $\mathrm{h}$ ", os dias de utilização semanais "ds" (de 1 a 7 ) e o "Preço por kWh".

A resistência por metro de condutor a utilizar na expressão anterior é a indicada na tabela 5 , tendo sido considerada a resistividade à temperatura de serviço.

\section{Conclusões}

A secção ótima de um circuito dependerá não só da corrente de serviço desse circuito e da corrente máxima admissível dos condutores, mas também da utilização em horas que lhe será dada.

Em situações onde existe uma "utilização intensiva" de um circuito, a opção por uma secção "ótima" em vez da secção “mínima tabelada" permite, não só um retorno rápido do investimento, mas também, após esse retorno, uma receita contínua através da poupança em perdas por efeito de Joule.

Tabela 5 - Resistência por metro de condutor

\begin{tabular}{|c|c|c|}
\hline Secção em mm² & Resistência por metro em Cobre & Resistência por metro em Alumínio \\
\hline 1,5 & 0,01500 & - \\
\hline 2,5 & 0,00900 & - \\
\hline 4 & 0,00563 & - \\
\hline 6 & 0,00375 & - \\
\hline 10 & 0,00225 & - \\
\hline 16 & 0,00141 & 0,00225 \\
\hline 25 & 0,00090 & 0,00144 \\
\hline 35 & 0,00064 & 0,00103 \\
\hline 50 & 0,00045 & 0,00072 \\
\hline 70 & 0,00032 & 0,00051 \\
\hline 95 & 0,00024 & 0,00038 \\
\hline 120 & 0,00019 & 0,00030 \\
\hline 150 & 0,00015 & 0,00024 \\
\hline 185 & 0,00012 & 0,00019 \\
\hline 240 & 0,00009 & 0,00015 \\
\hline 300 & 0,00008 & 0,00012 \\
\hline \multirow[t]{2}{*}{400} & 0,00006 & 0,00009 \\
\hline & $\rho_{\text {cobre }}=0,0225 \Omega \mathrm{mm}^{2} / \mathrm{m}$ & $\rho_{\text {alumínio }}=0,036 \Omega \mathrm{mm}^{2} / \mathrm{m}$ \\
\hline
\end{tabular}

